\title{
EXECUTIVE COMMITTEE WORKING GROUP WOMEN IN ASTRONOMY
}

\author{
CO-CHAIRS \\ MEMBERS
}

\author{
Anne J. Green, Sarah T. Maddison \\ Johannes Andersen, Olga B. Dluzhnevskaya, \\ Gloria M. Dubner, Andrea K. Dupree, \\ R. Elizabeth Griffin, W. Miller Goss, \\ Mary Kontizas, Birgitta Nordström, \\ Francesca Primas, Sylvia Torres Peimbert, \\ Yiping Wang, Shahinaz M. Yousef
}

BUSINESS MEETING AND WORKING LUNCH on 21 August 2006

\section{Introduction}

The second Women in Astronomy Lunchtime Meeting was held on Monday 21 August 2006, with more than 250 participants. The meeting was hosted by the EC Working Group for Women in Astronomy, established at the 2003 IAU General Assembly, and was attended by the current President, the Presidents-Elect for this and the next General Assembly, the General Secretary and Vice-Presidents, many senior astronomers, as well as students and young astronomers. It was a particular pleasure to welcome and congratulate the incoming President, Dr Catherine Cesarsky, the first woman to hold the position.

\section{Business Meeting report}

Lunch was preceded by the Business Meeting attended by the Organising Committee and an overflow audience of interested participants. Following discussion it was agreed that the Organising Committee should hold office for six years, in accordance with practice common among the Divisions. An important agenda item was the reporting on national statistics; one of the primary goals of the Working Group is the collection of global statistics on the status and position of women in astronomy. Several national reports were tabled, including from the United Kingdom, Latin America (organised from Argentina), Russia, Australia and Greece. We plan to survey the wider community with a concise and consistent set of questions relevant to all countries. For this, we need National Representatives who will take responsibility for obtaining the statistics. This will be quite complex to orchestrate, but we are fortunate that many surveys already exist and with the new ones that are planned, a comprehensive demographics database can be established.

It was noted that IAU gender statistics give an incomplete picture, but we cannot be satisfied with recent numbers showing overall only $13 \%$ women members from a total of 8000 in 39 countries, although an encouraging 22 nations recorded an increase since the previous General Assembly. The number of women who hold executive positions on the various IAU Committees is increasing, which is a welcome development.

\section{Lunch Meeting report}

The meeting theme was "Career Development for Women" with keynote speakers Dr Sunetra Giridhar of the Indian Institute of Astrophysics, Bangalore, and Dr Patricia Knezek, Deputy Director of the WIYN Observatory, Arizona. Every participant received a flyer showing the 1992 Baltimore Charter for Women in Astronomy, current IAU statistics and five suggested topics 
for discussion in the breakout groups and at the final Plenary session. Some of the issues and comments were:

\subsection{Unequal opportunity}

Has discrimination gone underground? Many participants wanted more flexible criteria for appointments, for more women to be appointed to senior positions and for the visibility of women at conferences to increase. In many instances, talented women are not even submitting applications for positions for which they would be competitive. Sadly, subtle discrimination is still a problem at several institutions.

\subsection{Mentoring and self-confidence}

Do women network effectively? Many young women astronomers expressed the need for role models and effective mentoring, to provide strategies to build self-confidence. Anecdotal evidence suggests women base their job and promotion applications on their achievements rather than on their potential (a more male approach).

\subsection{Family responsibilities}

Is there an easier time for having children? Many noted that the provision of childcare at workplaces and conferences is critical. While maternity leave is now frequently offered, arrangements for childcare at conferences and workplaces are often lacking. Women are still (generally) the primary caregivers, with greater vulnerability for research disruption and mobility limitations. This issue was raised by many of the participants.

\subsection{Dual careers}

Equal advancement of two careers is extremely difficult. Lack of mobility affects women more than men. How can we encourage more options for partners? Can we embrace non-standard career paths as acceptable? The two-body issue is seen as problematic for many women.

Following the meeting, a submission was made to the incoming IAU Executive with two action items for their consideration. The Working Group is keen to assist the Executive to achieve implementation of these items.

\section{Items for action}

\subsection{Increased visibility for women at conferences}

For all Symposia and scientific meetings, the IAU should strongly encourage the adequate representation of women as invited speakers, members of the Science Organising Committees and Session Chairs. Details of invitees to be provided as part of any meeting proposal.

\subsection{Childcare facilities at conferences}

Many women are constrained in their ability to attend scientific meetings by the lack of childcare provisions. The IAU would require that all future proposals for scientific meetings include some provision for childcare, most likely paid for by the participants, but organised by the hosts.

Finally, the meeting was an excellent if brief opportunity to exchange ideas and experiences, made possible through generous support from the US IAU National Committee for Astronomy and the National Organising Committee of the Prague General Assembly, for which we are greatly appreciative. We look forward to meeting again at the IAU XXVII General Assembly in Rio de Janeiro in 2009. 